\title{
Species richness in marine phytoplankton communities is not correlated to ecosystem productivity
}

\author{
Pedro Cermeño ${ }^{1, *}$, Tamara Rodríguez-Ramos ${ }^{2}$, Maria Dornelas ${ }^{3}$, \\ Francisco G. Figueiras ${ }^{4}$, Emilio Marañón ${ }^{2}$, Isabel G. Teixeira ${ }^{2}$, Sergio M. Vallina ${ }^{1}$ \\ ${ }^{1}$ Instituto de Ciencias del Mar (CSIC), Passeig Maritim de la Barceloneta 37-49, 08003 Barcelona, Spain \\ ${ }^{2}$ Departamento de Ecología y Biología Animal, Universidad de Vigo, 36310 Vigo, Spain \\ ${ }^{3}$ Centre for Biological Diversity, Scottish Oceans Institute, University of St Andrews, St Andrews, UK \\ ${ }^{4}$ Instituto de Investigaciones Marinas (CSIC), 36208 Vigo, Spain
}

\begin{abstract}
Microorganisms attain high population densities, which has led microplankton ecologists to assume that samples of a few tens of millilitres suffice to characterize the assemblage of species. However, the observation that microbial plankton communities contain a large pool of species with low population densities casts doubt on the validity of estimates based on conventional sampling methods. By standardizing estimates of species numbers, we show that marine phytoplankton communities have been undersampled more severely in ecosystems of low productivity, thus leading to bias in the patterns of diversity reported previously. We found that phytoplankton communities from unproductive, subtropical waters fit to right-skewed, lognormal species-abundance distributions, which has long been interpreted to arise from incomplete censuses. The sampling-standardized estimates of species richness show no relationship with ecosystem productivity, arguing against the idea that phytoplankton diversity peaks at intermediate levels of primary production. These results suggest that these 2 fundamental properties of marine phytoplankton communities, viz. diversity and productivity, might not be linked mechanistically.
\end{abstract}

KEY WORDS: Diversity-productivity relationship . Rarefaction ' Species abundance distribution . Undersampling written consent of the publisher

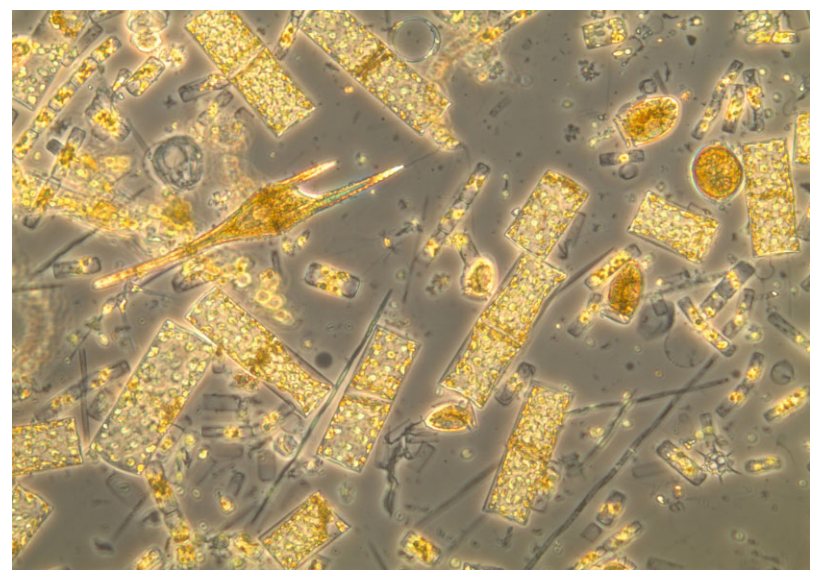

Phytoplankton communities are rich in species (pictured are diatoms and dinoflagellates from Ría de Vigo), but commonly used methods may have underestimated their true diversity.

Photo: I. G. Teixeira

\section{INTRODUCTION}

Understanding the relationship between diversity and productivity has important implications for the functioning of ecosystems. Field data and experimental analyses show that, for a variety of organism groups and habitat types, this relationship can adopt different patterns, including a monotonic increase/decrease, a hump-shaped curve or a lack of 
dependence (Waide et al. 1999, Mittelbach et al. 2001, Adler et al. 2011). Variations in the number of species among communities have been related to changes in the supply rate of resources that limit the production of biomass (Rosenzweig \& Abramsky 1993, Waide et al. 1999). Alternatively, it has been suggested that diverse communities, by increasing the array of physiological strategies, are more efficient in the use of resources and therefore should exhibit higher rates of production and community biomass (Fridley 2001, Hooper et al. 2005, Cardinale et al. 2009).

Roughly half of global primary production occurs in the oceans, mediated by the activity of free-living, photosynthetic microorganisms called phytoplankton (Field et al. 1998). Decades of taxonomic research and microscopy analyses have been instrumental in outlining the patterns of phytoplankton species distribution in aquatic ecosystems (Margalef 1997, Smayda \& Reynolds 2001, Widdicombe et al. 2010). These studies have underscored a hump-shaped, diversity-productivity relationship for marine phytoplankton (Irigoien et al. 2004, Smith 2007). Arguments to explain this relationship have focused primarily on the role of interspecific competition for resources. Whereas a suite of limiting resources control the number of species in ecosystems characterized by low resource supply (Interlandi \& Kilham 2001), a few fast-growing species dominate the exploitation of nutrients and light in productive ecosystems, and hence diversity is low in both unproductive and productive waters (Huisman et al. 1999, Irigoien et al. 2004). Maximum diversities are found in ecosystems dominated by intermediate levels of resource supply, reflecting a trade-off between competition, exploitation and grazing pressures that facilitates the coexistence of species (Floder \& Sommer 1999, Worm et al. 2002). Alternatively, Ptacnik et al. (2008) showed that the efficiency of resource use and thus carbon fixation increases with the diversity of phytoplankton communities in freshwater and brackish habitats, supporting the view that diversity enhances the productivity of the ecosystem.

Our current estimates of phytoplankton diversity might be biased by inadequate sampling designs. Conventional methods for the estimation of phytoplankton species richness include the collection of a small volume of seawater, which is examined under the microscope (Lund et al. 1958). However, such samples may contain orders of magnitude of difference in total abundance and biomass per unit volume, and therefore previous estimates of species numbers, based on roughly similar sampling volumes, are not strictly comparable (Gotelli \& Colwell 2001). These sampling issues might have limited our ability to delineate the patterns of microbial plankton diversity and identify the underlying mechanisms.

To explore this possibility, we analysed data of phytoplankton community composition and cell counts from coastal and open ocean environments spanning over 4 orders of magnitude in phytoplankton carbon biomass, which is used here as a surrogate for productivity. First, we standardized estimates of species numbers by constructing individual-based rarefaction curves (Gotelli \& Colwell 2001). Rarefaction analysis is commonly used to estimate the number of species within incompletely surveyed communities and is needed to compare the diversity of communities containing different densities of individuals (Magurran 2004). Secondly, we analysed the speciesabundance distribution (SAD) of communities in environments of contrasting productivity. A large body of theoretical work and data analyses suggest that right-skewed log-normal SADs might be the result of incomplete censuses (Preston 1948, Nee et al. 1991). Increased sampling effort progressively uncovers the genuine distribution, which tends to adopt a log-normal shape. Our analysis aims at identifying differences in the SADs of communities in contrasting marine environments, and between SADs resulting from conventional versus improved sampling methods.

\section{MATERIALS AND METHODS}

\section{Data collection}

We compiled data of species composition and abundance of eukaryotic phytoplankton communities from the Ría de Vigo (NW Iberian Peninsula, $42^{\circ} 14.09^{\prime} \mathrm{N}$, $8^{\circ} 47.18^{\prime} \mathrm{W}$; September 1990 to April $1992 ; \mathrm{n}=150)$, the Atlantic Iberian shelf $\left(42^{\circ} 7.8^{\prime} \mathrm{N}\right.$, $9^{\circ} 10.2^{\prime} \mathrm{W}$; May 2001 to April 2002; $\mathrm{n}=50$ ), the English Channel $\left(50^{\circ} 15^{\prime} \mathrm{N}, 4^{\circ} 13.02^{\prime} \mathrm{W}\right.$; January 2005 to June 2008; $\mathrm{n}=142$ ) and 3 latitudinal transects in the Atlantic Ocean (Atlantic Meridional Transect, AMT, 1-3) from $50^{\circ} \mathrm{N}$ to $50^{\circ} \mathrm{S}$ (September 1995 to October 1996; $\mathrm{n}$ =172). Data from the Ría de Vigo, Atlantic Iberian shelf and English Channel were obtained from seawater samples collected at the surface of the water column. AMT data were obtained from samples collected at the surface and the deep chlorophyll maximum. The combined data set spanned 4 orders of magnitude in phytoplankton cell density, carbon biomass and primary production. 


\section{Microscopy analyses}

At each station, 2 replicate seawater samples were preserved with $1 \%$ buffered formalin (to preserve calcium carbonate structures) and 1\% final concentration Lugol's iodine solution. A subsample of between 10 and $100 \mathrm{ml}$, based on sample fluorescence, was settled in a sedimentation chamber for $24 \mathrm{~h}$, and then cells were identified and counted under an inverted microscope (Lund et al. 1958). Cell counts were expressed as the number of individuals enumerated per species and per volume of seawater examined. Small flagellates (typically $<5-10 \mu \mathrm{m}$ diameter) were excluded from the analysis, as individual species within this group of small phytoplankton cannot be differentiated by obvious morphological criteria under the microscope.

Cell volume was calculated by assigning different geometric shapes that were most similar to the real shape of each phytoplankton species. Phytoplankton carbon biomass was calculated from known carbon to volume relationships determined on monospecific cultures in the laboratory (Menden-Deuer \& Lessard 2000).

\section{Non-parametric estimator of species richness}

The non-parametric species richness Chao 1 estimator (Chao1) adds a correction factor to the observed number of species (Chao 1984). Chao1 estimates total species richness as

$$
S_{\text {Chao1 }}=S_{\text {obs }}+\frac{n_{1}^{2}}{2 n_{2}}
$$

where $S_{\text {obs }}$ is the number of observed species, $n_{1}$ is the number of singletons (species observed once), and $n_{2}$ is the number of doubletons (species observed twice). This index is particularly useful for data sets skewed toward the low-abundance classes.

\section{Sampling standardization}

We constructed individual-based rarefaction curves. Rarefaction generates the expected number of species in a small collection of $\mathrm{n}$ individuals drawn randomly from a large pool of $\mathrm{N}$ individuals, and is needed to compare the diversity of communities containing different densities of individuals (Denslow 1995, Gotelli \& Colwell 2001, Magurran 2004). The method takes subsamples of 20 individuals without replacement until the entire community has been sampled. This routine is repeated 100 times and then the species accumulation curve is plotted as a function of increasing sample size. We represented the expected number of species after sampling a total of $\mathrm{n}=300$ individuals. Increasing the number of individuals sampled did not alter the results, although it substantially reduced the number of data points since many samples from unproductive waters had fewer than 500 individuals.

We also estimated the expected number of species by using the shareholder quorum sub-sampling (SQS) method (Alroy 2010). More diverse samples need more individuals to detect a similar proportion of the species present in the community, and thus a non-uniform sampling. SQS calculates the expected number of species by sampling a given, fixed coverage of the underlying $\mathrm{SAD}$, where coverage is the sum of the frequencies of the species sampled. We sampled $80 \%$ of the SAD for each community $(0.8$ quorum subsampling) after eliminating the most dominant taxa. Rarefaction and SQS routines were performed using the $\mathrm{R}$ functions rarefy and sqs ( $\mathrm{R}$ Development Core Team 2012).

\section{SADs}

We plotted the number of species per class of abundance for communities of coastal upwelling and the open ocean, subtropical gyres. Classes of abundance were represented as true doubling classes, with each successive octave containing twice the number of individuals as the preceding one.

We used probability distributions for discrete, random samples of individuals from the logseries and the Poisson lognormal distribution (Pielou 1969, Bulmer 1974, Connolly et al. 2005, Dornelas \& Connolly 2008), using the R functions nlimb and optim ( R Development Core Team 2012). The best fit distribution was selected using Akaike's information criterion, and the values predicted were plotted as described above for observed data. The observation that abundance data fit to a logseries or a Poisson lognormal distribution can be the result of insufficient sampling effort from an approximately lognormal distribution, or may indicate that the true underlying distribution is not lognormal.

\section{RESULTS}

The compilation of estimates of phytoplankton species richness does not support a hump-shaped diver- 

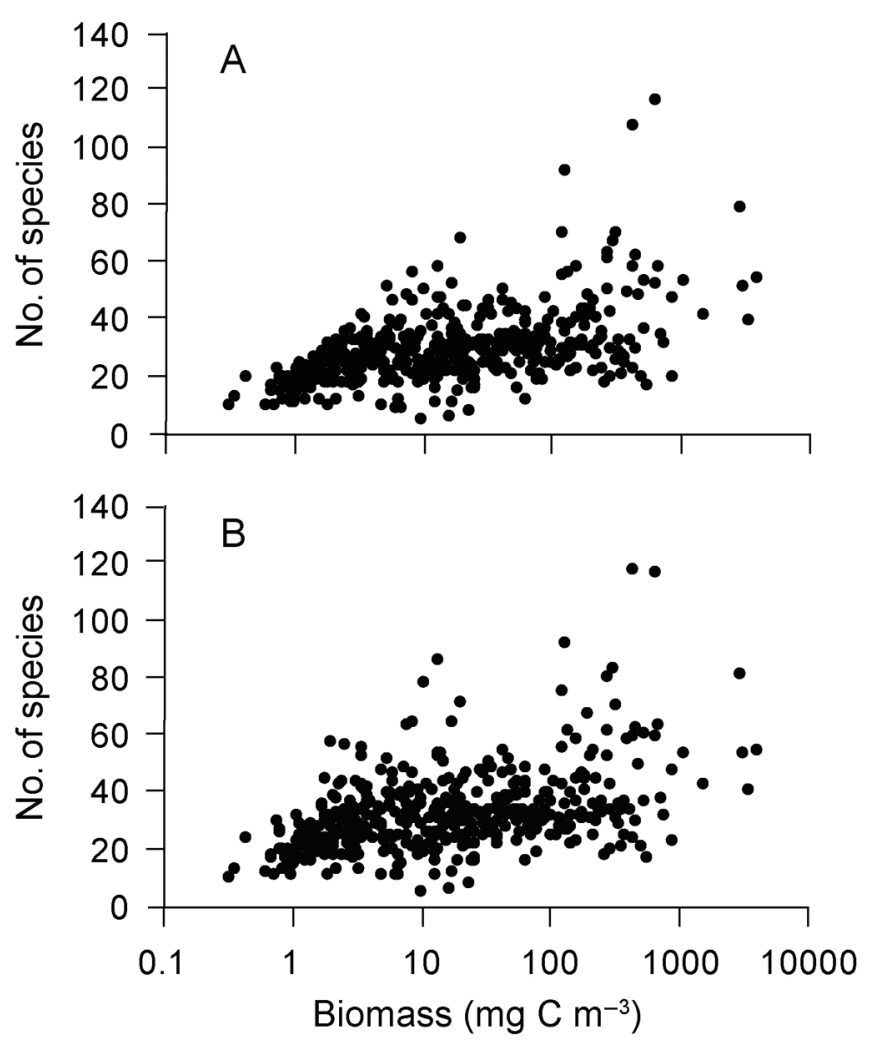

Fig. 1. (A) Raw estimates of phytoplankton species numbers from the Ría de Vigo, the Atlantic Iberian shelf, the English Channel and the open ocean plotted against phytoplankton carbon biomass. Each data point represents an individual community. (B) Estimates of species richness (using the same dataset as in panel A) based on the non-parametric estimator Chao1

sity-productivity relationship (Fig. 1A). Rather, our analysis of raw data shows that in some instances the number of species increased with the biomass of the community. Similar results were obtained by using Chao1, which adds a term based on the number of species represented by only 1 and 2 individuals (Fig. 1B). However, samples with high biomass concentration often contain larger population densities, and therefore, for a given volume of seawater, the sampling effort (i.e. the amount of individuals sampled) increases with the biomass of the sample.

To circumvent this limitation we constructed individual-based rarefaction curves. After standardizing diversity to the same number of individuals counted per site, we found no relationship between the number of species and the biomass of the community across the range of habitats included in the analysis (Pearson's correlation coefficient $r=0.013, p=0.785$; Fig. 2A). Standardizing the sampling effort to a fixed coverage of the underlying abundance distribution (the SQS method) did not result in any obvious rela-
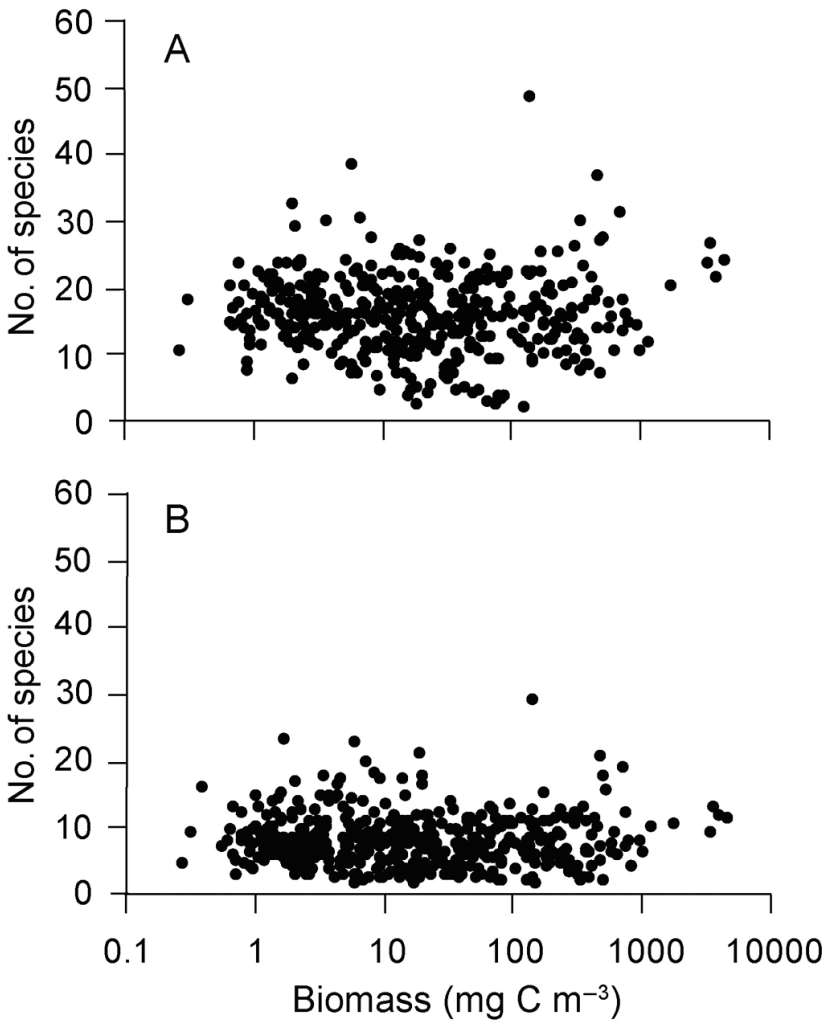

Fig. 2. (A) Sampling-standardized (rarefied) estimates of species richness plotted against phytoplankton carbon biomass. (B) Estimates of species richness produced by the shareholder quorum subsampling (SQS) method, in which a given proportion $(0.8)$ of the species-abundance distribution is sampled on each individual community

tionship between diversity and biomass $(\mathrm{r}=0.012$, $\mathrm{p}=0.79$; Fig. 2B). These results support the idea that ecosystem productivity (if biomass is used as a surrogate for productivity) is a poor predictor of marine phytoplankton species richness.

Our analyses suggest that phytoplankton communities were undersampled more severely in ecosystems of low productivity. To further test this possibility, we analysed the SAD of communities in environments of contrasting productivity such as coastal upwelling and the open ocean, subtropical gyres. In productive waters, phytoplankton communities exhibited a bimodal distribution, with higher diversities clustered around species of intermediate and low abundance (Fig. 3A, bars). In contrast, the SAD from subtropical communities tended to be lognormal in shape but truncated on the left (Fig. 3A, red line, Table 1), which has long been interpreted to arise from insufficient sampling effort and incomplete censuses (Preston 1948). In the subtropics, phytoplankton species attain extremely low popula- 

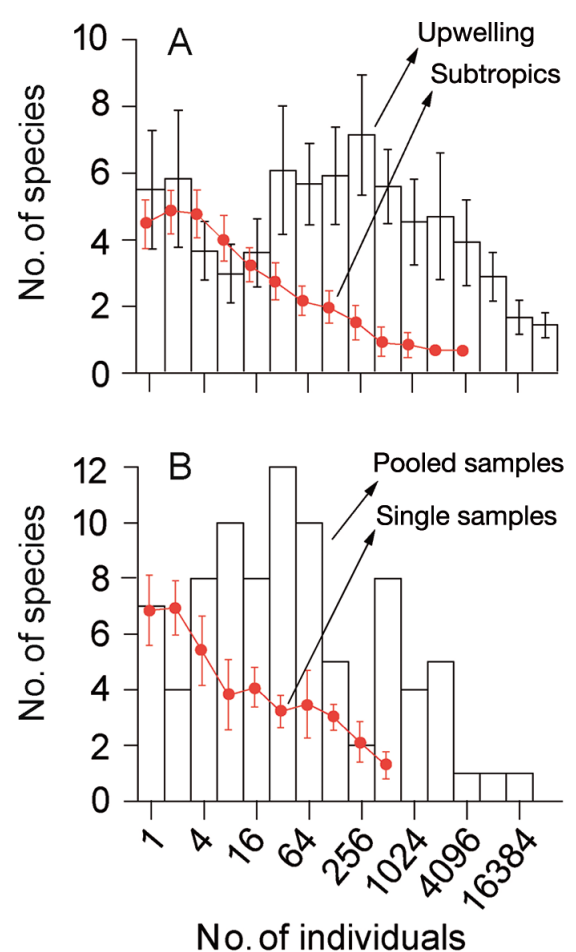

Fig. 3. (A) Mean number of species observed in each abundance class for communities of coastal upwelling in the Ría de Vigo (bars, $n=19$ ) and mean number of species predicted based on independent maximum-likelihood fits of the logseries and Poisson lognormal distributions to abundance data of subtropical communities (red lines, $\mathrm{n}=44$; see Table 1). Error bars are $95 \%$ confidence limits on mean number of species. The observation that subtropical data (red lines) fit to a Poisson lognormal distribution is indicative of insufficient sampling effort. (B) Unveiling the speciesabundance distribution of the Ría de Vigo. Bars represent the number of species in classes of abundance obtained by pooling 10 conventional $50 \mathrm{ml}$ seawater samples to amount to a volume of $500 \mathrm{ml}$. Red lines are the mean number of species predicted based on maximum-likelihood fits to abundance data obtained from conventional samples $(\mathrm{n}=10)$

tion densities, which makes their scrutiny under conventional sampling methods difficult. Conversely, as an ecosystem's productivity increases, the SAD moves towards classes of higher abundance, species are more easily scrutinized, and hence the genuine distribution emerges across what Preston called the 'veil line' (Preston 1948, p. 262).

To determine whether a lognormal abundance distribution emerges as sample size increases, we characterized the phytoplankton community of the Ría de Vigo during the low-productivity winter season by pooling together conventional seawater samples of $50 \mathrm{ml}$ ( $\mathrm{n}=10$ samples). Conventional sampling gave rise to a lognormal distribution with a right skew similar to that found in subtropical waters (Fig. 3B, red line). However, consistent with the model above, increased sampling effort added further species to the pool (Fig. 3B, bars), leading to a SAD more similar to that obtained in productive waters (Fig. 3A, bars).

The lack of correlation between diversity and biomass observed with the sample-based (fine-grain) data does not rule out the possibility of such correlation at a coarser scale. To explore this possibility, we repeated the rarefaction analyses after pooling together samples from regions of comparable productivity. Our analysis of data included low- and high-productivity regions along the AMT tracks, a mesotrophic station in the English Channel and a high-productivity coastal station in the Ría de Vigo. The sampling-standardized estimates of species richness did not show any obvious correlation with the average biomass of each region (Fig. 4). Species richness exhibited a decline with biomass across oligoand mesotrophic ecosystems, but increased again in the Ría de Vigo, the most productive ecosystem in our dataset. Although the scarcity of datasets limited the interpretation of the results, a priori, our analysis does not support the unimodal pattern between regional diversity and biomass.

\section{DISCUSSION}

A major issue with current estimates of microbial diversity is that sample sizes are smaller than the size of the communities (Woodcock et al. 2006). Systematic undersampling might have hampered the ability to correctly identify the spatial and temporal dynamics of microbial diversity and, more importantly, the underlying mechanisms (Azovsky \& Mazei 2012). This could mislead the interpretation of the relationship between diversity and productivity in marine phytoplankton. Traditionally, competitive mechanisms have been put forward to explain the response of phytoplankton diversity to changes in resource availability (Tilman 1982, Interlandi \& Kilham 2001). However, our analyses suggest a different view. Enhanced rates of resource supply and thus productivity usually lead to increased densities of certain populations (Fig. 3A). This is consistent with the observation that, for a given cell size, population densities increase over 2 orders of magnitude from subtropical waters to coastal upwelling systems (Cermeño et al. 2008). Yet, changes in the rate of resource supply had no apparent effect on our sampling-standardized estimates of species richness (Fig. 2A,B), which seem to be insensitive to changes in productivity. These results support the idea that processes operating at 
Table 1. Comparison of the fit of the log-series and Poisson lognormal distribution to abundance data of subtropical phytoplankton communities. Only data from samples collected at the surface were used in these analyses. AMT: Atlantic Merdional Transect, MLL: log-likelihood at the maximum likelihood estimate, AIC: Akaike's information criterion. Bold values denote the model selected based on the AIC

\begin{tabular}{|c|c|c|c|c|c|c|c|c|c|}
\hline \multirow[t]{2}{*}{ AMT } & \multirow{2}{*}{$\begin{array}{c}\text { Station } \\
\text { number }\end{array}$} & \multirow[t]{2}{*}{ Latitude } & \multicolumn{3}{|c|}{-Log-series } & \multirow[b]{2}{*}{ Mean } & \multicolumn{2}{|c|}{ Poisson lognorma } & \multirow[b]{2}{*}{ AIC } \\
\hline & & & $\alpha$ & MLL & AIC & & Sigma & MLL & \\
\hline 1 & 272 & $37.9^{\circ} \mathrm{N}$ & 5.38 & 151.1 & 304.2 & 1.26 & 2.61 & 149.1 & 302.3 \\
\hline 1 & 273 & $33.5^{\circ} \mathrm{N}$ & 5.74 & 142.7 & 287.3 & 4.18 & 2.25 & 141.4 & 286.7 \\
\hline 1 & 275 & $27.3^{\circ} \mathrm{N}$ & 5.17 & 121.8 & 245.5 & 2.77 & 2.33 & 122.3 & 248.5 \\
\hline 1 & 278 & $13^{\circ} \mathrm{N}$ & 5.10 & 98.9 & 199.8 & 2.16 & 2.34 & 98.5 & 201.1 \\
\hline 1 & 279 & $9.3^{\circ} \mathrm{N}$ & 5.17 & 106.2 & 214.4 & 2.22 & 2.30 & 105.3 & 214.6 \\
\hline 1 & 280 & $5.3^{\circ} \mathrm{N}$ & 6.48 & 106.1 & 214.2 & 3.35 & 2.58 & 104.2 & 212.4 \\
\hline 1 & 281 & $1.3^{\circ} \mathrm{N}$ & 5.36 & 121.4 & 244.8 & 3.23 & 2.15 & 119.7 & 243.5 \\
\hline 1 & 282 & $3^{\circ} \mathrm{S}$ & 5.35 & 118.4 & 238.7 & 0.50 & 3.00 & 116.9 & 237.8 \\
\hline 1 & 283 & $7^{\circ} \mathrm{S}$ & 5.30 & 122.9 & 247.7 & 2.52 & 2.25 & 121.2 & 246.4 \\
\hline 1 & 284 & $11.5^{\circ} \mathrm{S}$ & 5.81 & 121.3 & 244.6 & 3.53 & 2.37 & 120.2 & 244.4 \\
\hline 1 & 285 & $15.5^{\circ} \mathrm{S}$ & 5.81 & 91.7 & 185.3 & 15.11 & 1.72 & 90.4 & 184.7 \\
\hline 1 & 286 & $19.6^{\circ} \mathrm{S}$ & 5.35 & 129.7 & 261.3 & 2.69 & 2.49 & 130.6 & 265.2 \\
\hline 1 & 287 & $23.8^{\circ} \mathrm{S}$ & 6.11 & 125.5 & 252.9 & 3.74 & 2.25 & 122.3 & 248.6 \\
\hline 1 & 288 & $27.1^{\circ} \mathrm{S}$ & 5.41 & 130.7 & 263.4 & 2.13 & 2.05 & 124.9 & 253.7 \\
\hline 2 & 122 & $30.3^{\circ} \mathrm{S}$ & 4.11 & 94.2 & 190.5 & 5.73 & 1.38 & 93.2 & 190.4 \\
\hline 2 & 123 & $27.61^{\circ} \mathrm{S}$ & 6.90 & 114.4 & 230.8 & 12.29 & 2.09 & 112.0 & 227.9 \\
\hline 2 & 124 & $24.35^{\circ} \mathrm{S}$ & 6.28 & 118.9 & 239.8 & 4.94 & 2.30 & 116.7 & 237.5 \\
\hline 2 & 125 & $19.9^{\circ} \mathrm{S}$ & 5.17 & 74.8 & 151.6 & 5.64 & 2.05 & 75.4 & 154.7 \\
\hline 2 & 126 & $15.16^{\circ} \mathrm{S}$ & 5.60 & 88.2 & 178.4 & 2.24 & 2.26 & 85.7 & 175.4 \\
\hline 2 & 127 & $11.25^{\circ} \mathrm{S}$ & 3.40 & 49.3 & 100.6 & 0.14 & 2.73 & 49.5 & 103.0 \\
\hline 2 & 128 & $7.48^{\circ} \mathrm{S}$ & 5.74 & 122.4 & 246.8 & 7.01 & 2.00 & 121.0 & 246.1 \\
\hline 2 & 129 & $3.91^{\circ} \mathrm{S}$ & 6.71 & 89.3 & 180.7 & 3.04 & 2.42 & 85.9 & 175.7 \\
\hline 2 & 130 & $0.18^{\circ} \mathrm{S}$ & 6.11 & 113.4 & 228.9 & 4.77 & 2.05 & 109.6 & 223.2 \\
\hline 2 & 131 & $3.4^{\circ} \mathrm{N}$ & 4.24 & 74.1 & 150.3 & 8.88 & 1.14 & 71.8 & 147.5 \\
\hline 2 & 132 & $7.53^{\circ} \mathrm{N}$ & 6.51 & 113.4 & 228.7 & 7.23 & 2.39 & 112.6 & 229.2 \\
\hline 2 & 136 & $26.53^{\circ} \mathrm{N}$ & 5.55 & 122.4 & 246.8 & 10.85 & 1.77 & 121.3 & 246.5 \\
\hline 2 & 137 & $30.92^{\circ} \mathrm{N}$ & 5.36 & 136.3 & 274.6 & 4.45 & 2.18 & 136.3 & 276.6 \\
\hline 2 & 138 & $35.66^{\circ} \mathrm{N}$ & 6.20 & 175.4 & 352.9 & 5.02 & 2.45 & 174.6 & 353.3 \\
\hline 3 & 271 & $34.03^{\circ} \mathrm{N}$ & 7.31 & 149.0 & 300.0 & 1.82 & 3.03 & 144.7 & 293.4 \\
\hline 3 & 272 & $29.5^{\circ} \mathrm{N}$ & 5.95 & 146.2 & 294.4 & 1.48 & 2.63 & 142.3 & 288.6 \\
\hline 3 & 273 & $24.66^{\circ} \mathrm{N}$ & 6.49 & 205.7 & 413.4 & 6.44 & 2.26 & 201.9 & 407.9 \\
\hline 3 & 276 & $12.76^{\circ} \mathrm{N}$ & 9.80 & 174.5 & 351.0 & 0.58 & 3.92 & 164.5 & 333.0 \\
\hline 3 & 277 & $9.053^{\circ} \mathrm{N}$ & 5.22 & 113.3 & 228.5 & 6.46 & 1.95 & 113.6 & 231.1 \\
\hline 3 & 278 & $5.17^{\circ} \mathrm{N}$ & 6.46 & 160.5 & 323.1 & 6.73 & 2.02 & 155.1 & 314.1 \\
\hline 3 & 279 & $1.29^{\circ} \mathrm{N}$ & 6.77 & 179.6 & 361.1 & 10.26 & 2.14 & 175.9 & 355.8 \\
\hline 3 & 280 & $2.38^{\circ} \mathrm{S}$ & 6.52 & 158.2 & 318.4 & 0.66 & 3.26 & 154.6 & 313.2 \\
\hline 3 & 281 & $6.48^{\circ} \mathrm{S}$ & 5.36 & 128.4 & 258.8 & 5.10 & 2.07 & 127.9 & 259.9 \\
\hline 3 & 282 & $10.77^{\circ} \mathrm{S}$ & 6.53 & 127.7 & 257.5 & 2.39 & 2.63 & 124.3 & 252.6 \\
\hline 3 & 283 & $15.21^{\circ} \mathrm{S}$ & 6.34 & 122.4 & 246.7 & 7.33 & 2.09 & 119.8 & 243.5 \\
\hline 3 & 284 & $18.86^{\circ} \mathrm{S}$ & 6.56 & 115.4 & 232.9 & 8.31 & 2.38 & 115.1 & 234.2 \\
\hline 3 & 285 & $22.93^{\circ} \mathrm{S}$ & 7.10 & 157.9 & 317.8 & 0.19 & 3.72 & 151.2 & 306.4 \\
\hline 3 & 286 & $26.61{ }^{\circ} \mathrm{S}$ & 7.20 & 144.4 & 290.8 & 4.93 & 2.51 & 140.3 & 284.5 \\
\hline 3 & 287 & $29.85^{\circ} \mathrm{S}$ & 7.42 & 131.4 & 264.9 & 0.47 & 3.75 & 128.3 & 260.6 \\
\hline 3 & 288 & $32.8^{\circ} \mathrm{S}$ & 6.71 & 141.4 & 284.8 & 3.51 & 2.73 & 139.8 & 283.5 \\
\hline
\end{tabular}

regional scales, such as dispersal, override the importance of local factors such as competition for resources (Hillebrand \& Azovsky 2001, Fenchel \& Finlay 2004), flattening the patterns of diversity of eukaryotic microorganisms across the ocean.

Closed communities are predicted to achieve a steady-state number of species equal to the total number of limiting resources within the system
(Tilman 1982). Contrary to theory, field observations indicate that natural communities contain many more species than those predicted by competition models (Hutchinson 1961). To explain this apparent paradox, a number of mechanisms have been proposed, including the influence of environmental variability, chaotic fluctuations of population numbers (Huisman \& Weissing 1999), the production of 


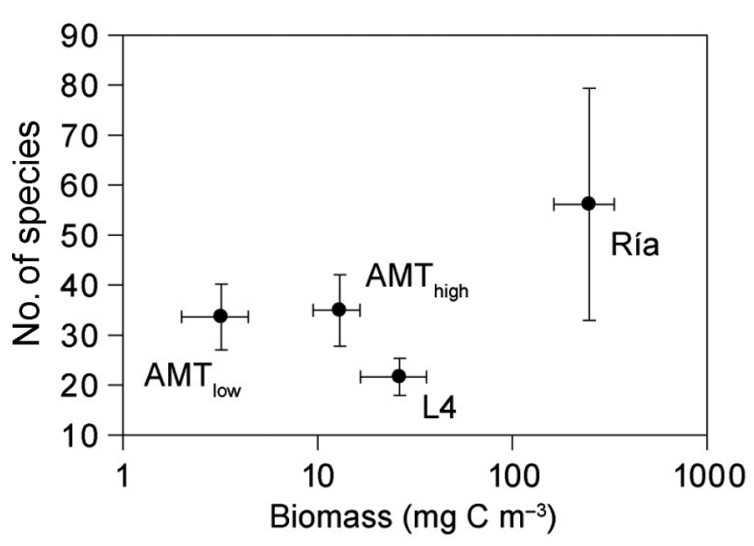

Fig. 4. Sampling-standardized estimates of regional species richness plotted against the average carbon biomass of each oceanic region. Error bars are $\pm 1 \mathrm{SD}$. The datasets used included low and high productivity regions along the Atlantic Meridional Transect tracks $\left(\mathrm{AMT}_{\text {low }}, \mathrm{AMT}_{\text {high }}\right)$, a mesotrophic station in the English Channel (L4) and a high productivity coastal station in the Ría de Vigo (NW Iberian Peninsula)

growth-inhibiting compounds (Roy \& Chattopadhyay 2007), variable resource supplies (Cermeño et al. 2011) or food web complexity (Worm et al. 2002). Recent observations indicate that microbial plankton communities contain a large pool of species with low population densities (Sogin et al. 2006, Caron \& Countway 2009). Yet, their occurrence has been systematically overlooked with traditional sampling methods. We suspect that mechanisms responsible for maintaining this pool of rare species, such as dispersal individuals, recurrent habitat re-colonization or selective grazing exert strong control on local species richness and might influence the relationship between diversity and productivity.

Our data analyses do not support the idea that phytoplankton diversity peaks at intermediate levels of community biomass. We have shown that previous estimates of phytoplankton species richness are biased by insufficient sampling effort, which explains the low diversity observed in unproductive ocean ecosystems, where the effects of undersampling are more severe. But why should species richness be low in ecosystems of high productivity? A priori, undersampling should not be a major issue in productive waters, where population densities are expected to be high. However, in many instances a large proportion of community biomass is accounted for by a few dominant species that exploit available resources and proliferate. We suggest that, as in unproductive ocean ecosystems, conventional sampling methods limit the scrutiny of species with low population densities, thereby producing low estimates of species richness.
The use of biomass as a surrogate for productivity may be problematic to establish the mechanisms underlying the relationship between diversity and productivity. The biomass of phytoplankton communities is the result of gain processes such as cell growth/division, and losses such as natural mortality, sinking or grazing. The extent to which these processes influence the diversity of phytoplankton communities is poorly understood and limits our ability to establish mechanisms from patterns. For example, a recent study shows that the relationship between diversity and productivity vanishes when phytoplankton biomass is controlled by algal consumers (Hillebrand \& Lehmpfuhl 2011). Grazing pressures depress the biomass and richness of phytoplankton communities, affecting their relationship with productivity. In addition to the rate of resource supply, the resource stoichiometry also influences the level of species coexistence. A previous study conducted on stream communities suggests that diversity increases when the input ratio of resources approximates to the optimal requirements of primary producers (Cardinale et al. 2009). Subsequent analyses have shown that the diversity of phytoplankton communities has a significant effect on the rate of biomass production, indicating that resource use efficiency is driven by species richness (Ptacnik et al. 2008). Finally, events of biomass accumulation such as phytoplankton blooms usually exhibit decreasing rates of carbon fixation. This is a common feature of post-bloom stages as inorganic nutrients in the bulk media become depleted and intracellular quotas decrease, which further complicates searching for a causal correlation among biomass, productivity and diversity. Thus, mechanisms such as top-down controls, resource stoichiometry or temporal lags in phytoplankton growth might contribute to shape the relationship between diversity and productivity. Yet, to adequately investigate the role of these mechanisms in nature, it is essential to obtain unbiased estimates of species richness, which are currently affected by sampling deficiencies.

Finally, the scale of analysis might dominate the shape of the relationship between diversity and productivity (Chase \& Liebold 2002). Our analysis points to a higher number of species in the eutrophic coastal ecosystem of the Ría de Vigo even after sampling standardization (Fig. 4). This might be the result of higher phytoplankton growth rates and thus a higher propensity for temporal variations in local species richness, or a higher probability of receiving immigrants from ecosystems containing high standing stocks. Coastal ecosystems typically exhibit a high 
degree of environmental heterogeneity which facilitates the succession of species and increases the dissimilarity between communities. Indeed, the Ría de Vigo is a highly dynamic coastal ecosystem influenced by events such as spring/summer upwelling and autumn/winter downwelling that almost certainly contribute to increase the hydrographic variability and hence the regional pool of species.

We have shown that conventional sampling methods can lead to biased estimates of marine phytoplankton species richness. Systematic undersampling has probably distorted the patterns of diversity reported previously, which highlights the need for building species-sample size curves to adequately compare the diversity of these microbial communities across space and through time. This will require additional efforts to scrutinize species with low population abundances by increasing the number of samples analysed or the volume of seawater considered (e.g. examining plankton net samples). Our analysis suggests that our current perception of phytoplankton diversity-productivity relationships in the ocean is the result of a sampling artefact. Thus, contrary to widespread perception, these 2 variables might not be related mechanistically. If so, these results can have significant implications for understanding the dynamics of phytoplankton diversity under different environmental or climatic scenarios. For example, if ocean warming reduces nutrient renewal and primary production, individual species will decrease their population densities with important consequences for the functioning of marine food webs and ocean biogeochemistry. Yet, our analysis suggests that these environmentally-driven changes in ocean primary production will have little impact on the patterns of local species richness.

Acknowledgements. We thank C. Marrasé and 3 anonymous reviewers for comments on the manuscript. AMT data collection was supported by the UK Natural Environmental Research Council through the Atlantic Meridional Transect consortium (NER/O/S/2001/00680). M.D. was supported by the ERC (BioTIME 250189). This research was funded by the Spanish Ministry of Economy and Competitiveness through project DISTRAL (CTM2011-25035).

\section{LITERATURE CITED}

Adler PB, Seabloom EW, Borer ET, Hillebrand H and others (2011) Productivity is a poor predictor of plant species richness. Science 333:1750-1753

> Alroy J (2010) The shifting balance of diversity among major marine animal groups. Science 329:1191-1194

>Azovsky A, Mazei Y (2012) Do microbes have macro- ecology? Large-scale patterns in the diversity and distribution of marine benthic ciliates. Glob Ecol Biogeogr 22:163-172

Bulmer MG (1974) On fitting the Poisson lognormal distribution to species-abundance data. Biometrics 30:101-110

Cardinale BJ, Bennett DM, Nelson CE, Gross K (2009) Does species diversity drive productivity or vice versa? A test of the multivariate productivity-diversity hypothesis in streams. Ecology 90:1227-1241

> Caron DA, Countway PD (2009) Hypotheses on the role of the protistan rare biosphere in a changing world. Aquat Microb Ecol 57:227-238

Cermeño P, Marañón E, Harbour D, Figueiras FG and others (2008) Resource levels, allometric scaling of population abundance, and marine phytoplankton diversity. Limnol Oceanogr 53:312-318

> Cermeño P, Lee JB, Wyman K, Schofield O, Falkowski PG (2011) Competitive dynamics in two species of marine phytoplankton under non-equilibrium conditions. Mar Ecol Prog Ser 429:19-28

Chao A (1984) Non-parametric estimation of the number of classes in a population. Scand J Stat 11:265-270

Chase JM, Liebold MA (2002) Spatial scale dictates the productivity-biodiversity relationship. Nature 416:427-430

> Connolly SR, Hughes TP, Bellwood DR, Karlson RH (2005) Community structure of corals and reef fishes at multiple scales. Science 309:1363-1365

> Denslow JS (1995) Disturbance and diversity in tropical rain forests: the density effect. Ecol Appl 5:962-968

> Dornelas M, Connolly SR (2008) Multiple modes in a coral species abundance distribution. Ecol Lett 11:1008-1016

Fenchel T, Finlay B (2004) The ubiquity of small species: patterns of local and global diversity. Bioscience 54: 777-784

Field CB, Behrenfeld MJ, Randerson JT, Falkowski P (1998) Primary production of the biosphere: integrating terrestrial and oceanic components. Science 281:237-240

> Floder S, Sommer U (1999) Diversity in planktonic communities: an experimental test of the intermediate disturbance hypothesis. Limnol Oceanogr 44:1114-1119

Fridley JD (2001) The influence of species diversity on ecosystem productivity: how, where, and why? Oikos 93: 514-526

Gotelli NJ, Colwell RK (2001) Quantifying biodiversity: procedures and pitfalls in the measurement and comparison of species richness. Ecol Lett 4:379-391

Hillebrand H, Azovsky AI (2001) Body size determines the strength of the latitudinal diversity gradient. Ecography 24:251-256

> Hillebrand H, Lehmpfuhl V (2011) Resource stoichiometry and consumers control the biodiversity-productivity relationship in pelagic metacommunities. Am Nat 178: 171-181

Hooper DU, Chapin FS, Ewel JJ, Hector A and others (2005) Effects of biodiversity on ecosystem functioning: a consensus of current knowledge. Ecol Monogr 75:3-35

Huisman J, Weissing FJ (1999) Biodiversity of plankton by species oscillations and chaos. Nature 402:407-410

- Huisman J, Jonker RR, Zonneveld C, Weissing FJ (1999) Competition for light between phytoplankton species: experimental tests of mechanistic theory. Ecology 80: 211-222

Hutchinson GE (1961) The paradox of the plankton. Am Nat 95:137-145

Interlandi SJ, Kilham SS (2001) Limiting resources and the 
regulation of diversity in phytoplankton communities. Ecology 82:1270-1282

Irigoien X, Huisman J, Harris RP (2004) Global biodiversity patterns of marine phytoplankton and zooplankton. Nature 429:863-867

Lund JWG, Kipling C, Cren ED (1958) The inverted microscope method of estimating algal numbers and the statistical basis of estimations by counting. Hydrobiologia 11:143-170

Magurran AE (2004) Measuring biological diversity. Blackwell, Oxford

Margalef R (1997) Our biosphere. In: Kinne O (ed) Excellence in ecology, Book 10. Ecology Institute, Oldendorf

Menden-Deuer S, Lessard EJ (2000) Carbon to volume relationships for dinoflagellates, diatoms, and other protist plankton. Limnol Oceanogr 45:569-579

Mittelbach GG, Steiner CF, Scheiner SM, Gross KL and others (2001) What is the observed relationship between species richness and productivity? Ecology 82:2381-2396

Nee S, Harvey PH, May RM (1991) Lifting the veil on abundance patterns. Proc R Soc Lond B Biol Sci 243:161-163

Pielou EC (1969) An introduction to mathematical ecology. Wiley, New York, NY

Preston FW (1948) The commonness, and rarity, of species. Ecology 29:254-283

Ptacnik R, Solimini AG, Andersen $T$, Tamminen $\mathrm{T}$ and others (2008) Diversity predicts stability and resource use efficiency in natural phytoplankton communities. Proc Natl Acad Sci USA 105:5134-5138

R Development Core Team (2012) R: a language and environment for statistical computing. $\mathrm{R}$ Foundation for Statistical Computing, Vienna

Editorial responsibility: Graham Savidge, Portaferry, UK
Rosenzweig ML, Abramsky Z (1993) How are diversity and productivity related? In: Ricklefs RE, Schluter D (eds) Species diversity in ecological communities. University of Chicago Press, London, p 52-65

Roy S, Chattopadhyay J (2007) Towards a resolution of 'the paradox of the plankton': a brief overview of the proposed mechanisms. Ecol Complex 4:26-33

Smayda TJ, Reynolds CS (2001) Community assembly in marine phytoplankton: application of recent models to harmful dinoflagellate blooms. J Plankton Res 23:447-461

Smith VH (2007) Microbial diversity-productivity relationships in aquatic ecosystems. FEMS Microbiol Ecol 62: 181-186

Sogin ML, Morrison HG, Huber JA, Welch DM and others (2006) Microbial diversity in the deep sea and the underexplored 'rare biosphere'. Proc Natl Acad Sci USA 103: $12115-12120$

Tilman D (1982) Resource competition and community structure. Princeton University Press, Princeton, NJ

- Waide RB, Willig MR, Steiner CF, Mittelbach G and others (1999) The relationship between productivity and species richness. Annu Rev Ecol Evol Syst 30:257-300

> Widdicombe CE, Eloire D, Harbour D, Harris RP, Somerfield PJ (2010) Long-term phytoplankton community dynamics in the Western English Channel. J Plankton Res 32: 643-655

- Woodcock S, Curtis TP, Head IM, Lunn M, Sloan WT (2006) Taxa-area relationships for microbes: the unsampled and the unseen. Ecol Lett 9:805-812

> Worm B, Lotze HK, Hillebrand H, Sommer U (2002) Consumer versus resource control of species diversity and ecosystem functioning. Nature 417:848-851

Submitted: November 7, 2012; Accepted: June 10, 2013

Proofs received from author(s): July 5, 2013 